\title{
Effect of Yttrium Substitution on Superconductivity in Bi-2212 Textured Rods Prepared
} by LFZ Technique

B. Özçelik ${ }^{* a}$, O. Nane ${ }^{b}$, A. Sotelo ${ }^{c}$, M. A. Madre ${ }^{c}$

${ }^{a}$ Department of Physics, Faculty of Sciences and Letters, Çukurova University. 01330 Adana, Turkey

${ }^{\mathrm{b}}$ Department of Material Science and Engineering, Faculty of Engineering, Hakkari University, 30000 Hakkari, Turkey

c ICMA (CSIC-Universidad de Zaragoza). María de Luna, 3. 50018 Zaragoza, Spain.

\begin{abstract}
s
In this study, the physical and superconducting properties of the $\mathrm{Bi}_{2} \mathrm{Sr}_{2} \mathrm{Ca}_{1-\mathrm{x}} \mathrm{Y}_{\mathrm{X}} \mathrm{Cu}_{2} \mathrm{O}_{8+\delta}$ with $\mathrm{x}=0.0,0.05,0.0750 .1$, and 0.20 textured superconducting rods prepared by a laser floating zone technique were presented. The effect of $\mathrm{Y}^{3+}$ substitution for $\mathrm{Ca}^{2+}$ has been investigated by X-ray diffraction (XRD), scanning electron microscopy (SEM), energy dispersive X-ray spectroscopy (EDX), dc-magnetization, magnetic hysteresis and critical current density calculation by using the Bean's critical state model. The powder XRD patterns of samples show that Bi-2212 phase is the major one. Along with the powder samples, the textured rod surfaces also were investigated by XRD. The grains found to be well-oriented along the longitudinal rod axis which is a typical result for superconductors prepared by laser floating zone (LFZ) method, has been observed. The best critical temperature, $T_{C}$, has been found as 92.9 K for the sample with $0.15 Y$ substitution, under DC magnetic field of 50 Oe in ZFC mode. It has also been observed that the critical current density decreases with increasing Ysubstitution. Using those values, the maximum $J_{C}$ value has been determined as $2.37 \times 10^{5}$ $\mathrm{A} / \mathrm{cm}^{2}$ for the undoped sample.
\end{abstract}

\section{Keywords}

Magnetic Properties, Bi-2212, Yttrium Substitution, Critical Current Density J Floating Zone Technique. 


\section{Introduction}

The BSCCO family can be described using the $\mathrm{Bi}_{2} \mathrm{Sr}_{2} \mathrm{Ca}_{n-1} \mathrm{Cu}_{n} \mathrm{O}_{2 n+4+y}$ general formula, where $\mathrm{n}=1,2$, and 3 . The $\mathrm{n}$ value indicates the number of $\mathrm{CuO}_{2}$ layers in the crystal structure, producing the $\mathrm{Bi}-2201, \mathrm{Bi}-2212$ and $\mathrm{Bi}-2223$ phases with critical temperatures, $T c$ 's, of about 20, 85, and $110 \mathrm{~K}$, respectively [1,2]. Since their discovery, many experiments have been performed to better understand their structural and physical properties of the system, and to improve their critical temperature $(T c)$ and critical current density $\left(J_{c}\right)$ [3-21]. After these works, it is well-known that the Bi-2212 phase is the most stable and easy to prepare among the high-Tc phases. It exists in a wide range of compositions and processing temperatures, when compared with the $\mathrm{Bi}-2223$ phase. On the other hand, Tc of $\mathrm{Bi}-2212$ phase can be modified by its cationic composition and oxygen content, i.e. it clearly increases when the Bi and Ca contents are decreased [22].

Besides BSCCO superconductors have some advantages as high critical temperature and magnetic field carrying capacity, they also have some disadvantages as the weak-links, high anisotropy, and small coherence length. These phenomena restrict them for massive technological applications. Generally, a negative effect on $J_{C}$ values can be produced by very small misorientation of grains in these materials. As a consequence, many different strategies have been tested to overcome those disadvantages and maximize the transport properties at 77 $\mathrm{K}$. One of the most promising ways to improve their transport properties is inducing an adequate grain orientation via texturing methods. Among these methods, it is possible to distinguish between solid state texturing, as the hot-pressing technique [23,24], and directional solidification from the melt, as the laser floating zone (LFZ) or the electrically assisted laser floating zone (EALFZ) [25,26]. Among these methods, the LFZ has been shown as very effective to produce a good grain orientation in $\mathrm{Bi}-2212$ superconductors $[3,5,6,14,27]$. This method is characterized for producing very high thermal gradients in the solidification front, leading to a preferential alignment of grains with their c-axis perpendicular to the growth direction [28] and, as a consequence, maximizing the transport properties along the growth axis.

In this study, $\mathrm{Bi}_{2} \mathrm{Sr}_{2} \mathrm{Ca}_{1-\mathrm{x}} \mathrm{Y}_{\mathrm{x}} \mathrm{Cu}_{2} \mathrm{O}_{8+\delta}$ textured ceramics with different $\mathrm{Y}$ content have been prepared by the LFZ technique. The effect of $\mathrm{Y}$ on $T_{C}$, magnetic properties, magnetic $J_{C}$, and microstructural features has been investigated. 


\section{Experimental}

The initial $\mathrm{Bi}_{2} \mathrm{Sr}_{2} \mathrm{Ca}_{1-\mathrm{x}} \mathrm{Y}_{\mathrm{x}} \mathrm{Cu}_{2} \mathrm{O}_{8+\delta}(\mathrm{x}=0.0,0.05,0.075$ 0.1, and 0.20) polycrystalline materials used in this work were prepared using the classical solid-state route from commercial $\mathrm{Bi}_{2} \mathrm{O}_{3}$ (Panreac, 98 + \%), $\mathrm{SrCO}_{3}$ (Panreac, 98 \%), $\mathrm{CaCO}_{3}$ (Aldrich, $\geq 99 \%$ ), $\mathrm{Y}_{2} \mathrm{O}_{3}$ (Sigma-Aldrich, $99.99 \%$ ), and $\mathrm{CuO}$ (Panreac, 99 \%). They were weighed in the appropriate proportions and ball milled in an agate ball mill in acetone media at $300 \mathrm{rpm}$ for $30 \mathrm{~min}$. The slurry was then introduced in a rapid drying system equipped with infrared radiation until all the acetone has been evaporated. The resulting homogeneous mixture was then manually milled in order to break the agglomerates, leading to easier alkaline-earth carbonates decomposition in the next steps. The soft powder was subsequently calcined at 750 and $800{ }^{\circ} \mathrm{C}$ for $12 \mathrm{~h}$ with an intermediate manual milling. This step has been proven in previous works to be adequate to totally decompose the Sr and Ca carbonates [29]. This is due to the fact that if carbonates are present in the LFZ process, they would decompose in the molten zone, producing $\mathrm{CO}_{2}$ bubbles and destabilizing the crystallization front [30]. As a consequence, smaller grain sizes, higher amount of secondary phases and grain misalignment would be produced in the bulk samples. Other effect of this carbonates decomposition could be the formation of porosity by trapping the bubbles in the solidification front, decreasing the effective section for electrical conduction.

Once the powders were thermally treated, they were isostatically pressed in form of long cylinders (between 2 and $3 \mathrm{~mm}$ diameter and $100 \mathrm{~mm}$ length) at $200 \mathrm{MPa}$. These cylinders were then used as feed in a directional solidification process performed in a LFZ installation described elsewhere [31]. The textured cylindrical bulk samples were obtained using a continuous power Nd:YAG laser $(\lambda=1.064 \mu \mathrm{m})$, under air atmosphere, at a growth rate of 30 $\mathrm{mm} / \mathrm{h}$. Moreover, the seed has been clockwise rotated at $3 \mathrm{rpm}$ to maintain the cylindrical geometry while the feed has been rotated in the opposite direction at $15 \mathrm{rpm}$ to homogenize the molten zone, as reported in previous works [32]. After the melt-grown processes, long and geometrically very homogeneous bars were obtained (120 mm length and $2 \mathrm{~mm}$ diameter).

On the other hand, as it is well-known, Bi-2212 ceramic presents incongruent melting producing different secondary phases [33]. As a consequence, a thermal treatment is necessary to obtain the superconducting phase after the directional solidification process. This annealing process was performed under air atmosphere and consisted in two steps: $860{ }^{\circ} \mathrm{C}$ for $60 \mathrm{~h}$ in order to form the Bi-2212 phase, followed by $800{ }^{\circ} \mathrm{C}$ for $12 \mathrm{~h}$ to adjust the oxygen content and, finally, quenched in air to room temperature [34]. 
Structural studies of textured ceramic samples were performed by using a Rigaku D/max-B $\mathrm{X}$-ray powder diffractometer (CuK $\alpha$ radiation) with $2 \theta$ ranging between 3 and 80 degrees. The uncertainty of the crystal lattice parameters calculation remained in the \pm 0.00001 range. Microstructural features were determined on polished longitudinal cross-sections of samples, in a field emission scanning electron microscope (FESEM, Zeiss Merlin) equipped with an energy dispersive spectroscopy (EDX) system. The magnetic hysteresis measurements of samples were performed at temperature of $10 \mathrm{~K}$ and an applied field of $\pm 1 \mathrm{~T}$, and $\mathrm{M}(\mathrm{T})$ measurement obtained under applied fiel of 50 Oe in ZFC mode with a 7304 model Lake Shore VSM.

\section{Results and Discussion}

Figure 1 shows the powder XRD patterns performed on textured and annealed rod samples. It can be clearly seen in the graph that major phase is the superconducting Bi-2212 (peaks labeled by +). Moreover, small amounts of unreacted $\mathrm{Y}_{2} \mathrm{O}_{3}$ (ICSD Card no:01-074-1828) were detected in the samples. The unit-cell parameters of Bi-2212 phase were calculated by least square fitting and the results are given in Table 1 . The crystal symmetries of all samples obtained as pseudo-tetragonal structure with a parameter of $a-b \approx 5.40 \dot{\mathrm{A}}$. The $c$-parameter of all samples is found in the vicinity of $30.8 \dot{\mathrm{A}}$, which is in good agreement with the reported for $\mathrm{Bi}-2212$ single crystals [35]. The $a$ and $b$ lattice parameters remain unchanged while $\mathrm{c}$ parameter slightly decreases with increasing Yttrium substitution. Moreover, the crystal sizes of all samples are calculated by using the Debye-Scherrer formula [36], and listed in Table 1. The average grain size first increases with increasing of yttrium concentration until 0.075, decreasing again for higher Y-content. As a result, it can be deduced that a small amount of yttrium substitutions may help to the growth mechanism of Bi-2212 phase. On the other hand, increasing Y-content can inhibit grain growth by the formation secondary phases.

Figure 2 shows XRD patterns of samples obtained in the rods surface. The indexed peak positions indicate that main peaks correspond to the (00l) lines of $\mathrm{Bi}-2212$ phase for all the samples. This implies that c-axis of Bi-2212 phase are perpendicular to the growth direction. SEM images corresponding to longitudinal polished sections of samples have been obtained and presented in Fig. 3. SEM and EDX observations performed on the different samples have shown that they are composed of different contrasts, indicating the different phases in the structures. From this figure, it can be clearly seen that Bi-2212 (grey phase indicated by \#1) is the major phase in all samples, in agreement with the XRD data. The phase marked as \#2 (white contrast) has been identified as Bi-2201 phase. Black spots marked as \#3 correspond to 
unreacted $\mathrm{CaO}$. Finally, dark grey contrast marked as \#4 indicates $\mathrm{Ca}+\mathrm{Y}$ rich phase without Bi. Moreover, SEM images show the good grain alignment for all samples.

Figure 4 show the magnetization as a function of temperature for all concentrations. In this figure it can be clearly observed that the critical onset temperature, $T_{C}{ }^{\text {on }}$, is almost the same $(\approx 92 \mathrm{~K})$ with a sharp drop for all samples. On the other hand, according to inset figure, it can be concluded that the sample having $0.15 \mathrm{Y}$ substitution show the highest $T_{C}{ }^{\text {on }}$ value $(92.9 \mathrm{~K})$. This result is in good agreement with the XRD obtained on the rods surface, indicating that 0.15Y substitution for $\mathrm{Ca}$ is the optimal one to produce well textured and c-axis oriented samples. On the other hand, it is well-known that the texturing process improves the carrying capacity of current, thus the critical current circulating along the sample in the diamagnetic mode can show a good performance under an applied magnetic field. In order to determine the critical current values for the samples $M-H$ measurements have been performed on all samples.

Figure 5 shows the magnetic hysteresis loops measured at $10 \mathrm{~K}$, between \pm 9 T applied perpendicular to the growth direction. The general appearance of this figure indicates that there is a distinct dependence of magnetization values with Y-substitution. In addition, the hysteresis loops are generally getting narrow with increasing yttrium concentration level. Furthermore, the reversible and symmetrical shapes of loops imply that pinning mechanism commonly occurs by bulk pinning rather than surface and geometrical barriers in low fields [37]. According to the comparison between $M-H$ and $M-T$ measurements, there is an incompatibility. When yttrium concentration is increased up to $\mathrm{x}=0.1$, it produces higher $T_{C}$ samples, with well textured and c-axis oriented structure. It should be emphasized that yttrium helps forming crystalline structures on the surface of the rods with small thickness. It is confirmed by a current circulating on surface of specimen with a London penetration depth, $\lambda$, at small field of around 50 Oe in the $M-T$ measurements. When higher fields are applied for $M-H$ measurements, the magnetic field penetrates from well textured regions to the lower textured ones inside the rod. Therefore, the resistivity starts to increase thus diamagnetic response declines. On the other hand, a decrease of magnetic moment in hysteresis loops with increasing Y content has been obtained.

The critical current density, $J_{C}$, values of all the samples were calculated from the hysteresis data measured at $10 \mathrm{~K}$, using the Bean's model [38].

Ic $=30 \frac{\Delta \mathrm{M}}{d}$ 
where $J_{C}$ is the critical current density in ampéres per square centimeter of a sample. $\Delta M=M_{+}$ - $M_{\text {. }}$ is measured in electromagnetic units per cubic centimeter, and $d$ is the thickness of the sample.

Figure 6 shows that the calculated $J_{C}$ values of all the samples at $10 \mathrm{~K}$. According to these data, it can be deduced that yttrium substitution in the Bi-2212 system does not contribute to the pinning mechanism. Thus, at $10 \mathrm{~K}$ and absence of the magnetic field, the pure sample exhibits the highest $J_{C}$ value, $2.37 \times 10^{5} \mathrm{~A} / \mathrm{cm}^{2}$. Moreover, $J_{C}$ decreases with increasing of yttrium substitution and magnetic field. This behavior can be related to the presence of grain boundaries, weak-links, and structural defects, etc.

\section{Conclusions}

This study reports on the experimental results of Y-substitution for Ca in $\mathrm{Bi}_{2} \mathrm{Sr}_{2} \mathrm{Ca}_{1-x} \mathrm{Y}_{x} \mathrm{Cu}_{2} \mathrm{O}_{y}$ ( $\mathrm{x}=0.0,0.05,0.0750 .1$, and 0.20 ) superconductor prepared by conventional solid state route and then directionally grown using the laser floating zone technique. SEM micrographs and EDX results obtained on longitudinal polished sections of rods indicate that $\mathrm{Bi}-2212$ is the major phase in all samples, which has been confirmed by powder XRD. On the other hand, XRD data obtained on the surface of rods reveals a very well oriented crystalline structure on the surface in the yttrium substituted samples. This statement supports the super-current circulation on the surface at small magnetic fields and improves the diamagnetic response, resulting in higher $T_{C}$ when compared to the pure samples. However, magnetic hysteresis results indicate that yttrium substitution cannot help producing this structure inside the rods, and increasing Y content might have weakened the grains orientation inside the rods, decreasing the superconducting properties of samples. This result has been confirmed by the calculation of critical current density by Bean model which shows a decrease on $J_{C}$ values by increasing yttrium substitution level.

\section{Acknowledgements}

This work is supported by Research Fund of Çukurova University, Adana, Turkey, under grant contracts no: FBA-2015-3934. A. Sotelo and M. A. Madre acknowledge the Gobierno de Aragón and Fondo Social Europeo (Grupo de Investigacion Consolidado T12) and MINECO-FEDER (MAT2013-46505-C3-1-R) for financial support. M. A. Madre also acknowledges MINECO-FEDER (Project ENE2014-52105-R) for funding. Authors would like to acknowledge the use of Servicio General de Apoyo a la Investigación-SAI, Universidad de Zaragoza. 


\section{References}

[1] C. Michel, M. Hervieu, M.M. Borel, A. Grandin, F. Deslands, J. Provost, B. Raveav, Z. Phys. B 86, 421 (1987)

[2] H. Maeda, Y. Tanaka, M. Fukutumi, T. Asano, Jpn. J. Appl. Phys. 27, 209 (1988)

[3] B. Özçelik, C. Kaya, H. Gündoğmuş, A. Sotelo, M.A. Madre, J Low Temp Phys. 174, 136 (2014)

[4] N. Türk, H. Gündogmus, M. Akyol, Z. D. Yakıncı, A. Ekicibil, B. Özçelik J Supercond Nov Magn27, 711 (2014)

[5] A. Özaslan, B. Özçelik, B. Özkurt, A. Sotelo,M.A. Madre, J Supercond Nov Magn 27, 53 (2014)

[6] H.Gündoğmuş, B. Özçelik, A. Sotelo, M. A. Madre J Mater Sci: Mater Electron 24, 2568, (2013)

[7] V. Lennikov, B. Özkurt, L. A. Angurel, A. Sotelo, B. Özçelik, G. F. de la Fuente, J Supercond.Nov.Magn. 26, 947, (2013)

[8] B. Özçelik, B. Özkurt, M.E. Yakıncı, A. Sotelo, M. A. Madre, J Supercond Nov Magn. 26:873 (2013)

[9] D. Yazıcı, B. Ozçelik, M.E. Yakıncı, J. Low Temp. Phys. 163, 370 (2011)

[10] A. Sotelo, M. Mora, M. A. Madre, J. C. Diez, L. A. Angurel, G. F. de la Fuente, J. Eur. Ceram. Soc. 25, 2947 (2005)

[11] A. Sotelo, P. Majewski, H. S. Park, F. Aldinger, Physica C 272, 115 (1996)

[12] M. Mora, A. Sotelo, H. Amaveda, M. A. Madre, J. C. Diez, L. A. Angurel, G. F. de la Fuente, Bol. Soc. Esp. Ceram. V. 44, 199 (2005)

[13] G. F. de la Fuente, A. Sotelo, Y. Huang, M. T. Ruiz, A. Badia, L. A. Angurel, F. Lera, R. Navarro, C. Rillo, R. Ibañez, D. Beltran, F. Sapiña, A. Beltran, Physica C185, 509 (1991)

[14] B. Özkurt, M. A. Madre, A. Sotelo, M.E. Yakıncı, B. Özçelik, J. Supercond. Nov. Magn. 25, 799 (2012)

[15] S. Bal, M. Dogruer, G. Yıldırım, A. Varilci, C. Terzioglu, Y. Zalaoglu, J. Supercond. Nov. Magn. 25, 847 (2012)

[16] B.Ozkurt, J Mater Sci: Mater Electron., 24, 2426 (2013)

[17] B. Özçelik, M.Gürsul, A. Sotelo, M. A. Madre, J. Mater. Sci.: Mater. Electron. 25, 4476 (2014)

[18] B. Özçelik, M.Gürsul, A. Sotelo, M. A. Madre, J. Mater. Sci.: Mater. Electron. 26, 441 (2015) 
[19] B. Özçelik, M.Gürsul, A. Sotelo, M. A. Madre, J. Mater. Sci.: Mater. Electron. 26, 2830 (2015)

[20] B. Özçelik, E.Yalaz, M.E.Yakıncı, A. Sotelo, M. A. Madre, J. Mater. Sci.: Mater. Electron. 28, 553 (2015)

[21] M.Gürsul, A. Ekicibil, B. Özçelik, M. A. Madre, A. Sotelo, J Supercond Nov Magn DOI 10.1007/s10948-015-2977-X

[22] P. Majewski, H. L. Su, M. Quilitz, J. Mater. Sci. 32, 5137 (1997)

[23] V. Garnier, R. Caillard, A. Sotelo, G. Desgardin, Physica C 319, 197 (1999)

[24] J. G. Noudem, E. Guilmeau, D. Chateigner, B. Ouladdiaf, D. Bourgault, Physica C 408, 862 (2004)

[25] Y. Huang, G. F. de la Fuente, A. Sotelo, A. Badía, F. Lera, R. Navarro, C. Rillo, R. Ibañez, D. Beltrán, F. Sapiña, A. Beltrán, Physica C 185, 2401 (1991)

[26] F. M. Costa, N. M. Ferreira, Sh. Rasekh, A. J. S. Fernandes, M. A. Torres, M. A. Madre, J. C. Diez, A. Sotelo, Crystal Growth Design. 15, 2094 (2015)

[27] A. Sotelo, M. Mora, H. Amaveda, J. C. Diez, L. A. Angurel, M. C. Mayoral: Bol. Soc. Esp. Ceram. V. 45, 228 (2006)

[28] G. F. de la Fuente, M.T. Ruiz, A. Sotelo, A. Larrea, R. Navarro: Mater. Sci. Eng. A 173, 201 (1993)

[29] H. Gundogmus, B. Ozcelik, B. Ozkurt, A. Sotelo, M.A. Madre, J. Supercond. Nov. Magn. 26, 111 (2013)

[30] A. Sotelo, Sh. Rasekh, M. A. Madre, J. C. Diez, J. Supercond. Nov. Magn. 24, 19 (2011)

[31] M. F. Carrasco, F. M. Costa, R. F. Silva, F. Gimeno, A. Sotelo, M. Mora, J. C. Diez, L. A. Angurel, Physica C 415, 163 (2004)

[32] M. Mora, A. Sotelo, H. Amaveda, M. A. Madre, J. C. Diez, F. Capel, J. M. LopezCepero, J. Eur. Ceram. Soc. 27, 3959 (2007)

[33] M. A. Madre, H. Amaveda, M. Mora, A. Sotelo, L. A. Angurel, J. C. Diez, Bol. Soc. Esp. Ceram. V. 47, 148 (2008)

[34] C. Kaya, B. Ozcelik, B. Ozkurt, A. Sotelo, M. A. Madre, J. Mater. Sci.: Mater. Electron. 24, 1580 (2013)

[35] X. Zhao, Physica C 320, (1999)

[36] P. Scherrer, Göttinger Nachrichten Gesell 2 (1918)

[37] B. Özkurt, A. Ekicibil, M. Ali Aksan, B. Özçelık, M. E. Yakıncı,K. Kiymaç, J. Low Temp Phys, 149: 105-118. (2007)

[38] C.P. Bean, Phys. Rev. Lett. 8, 250 (1962) 


\section{Figure captions}

Figure 1. Powder XRD patterns of all the samples. Peaks corresponding to the $\mathrm{Bi}-2212$ and $\mathrm{Y}_{2} \mathrm{O}_{3}$ phases are indicated by + and $*$ respectively.

Figure 2. XRD patterns of surfaces of the rod samples.

Figure 3. SEM micrographs performed on longitudinal polished sections of all samples.

Figure 4. Magnetic moment as a function of temperature for different Y-concentrations.

Figure 5. Magnetic Hysteresis curves obtained for the all samples at $10 \mathrm{~K}$.

Figure 6. Calculated critical current densities, Jc, of the samples, as a function of applied field at $10 \mathrm{~K}$. 
Table 1. $T_{C}$ values determined from $M-T$ measurement, unit-cell parameters, and crystal size values for all samples.

\begin{tabular}{|c|c|c|c|c|}
\hline Y-addition & $T_{C}(\mathrm{~K})$ & $\begin{array}{l}\text { Unit-cell Parameter } a \approx b \\
(\dot{\mathrm{A}})\end{array}$ & $\begin{array}{l}\text { Unit-cell Parameter } \\
c\end{array}$ & $\begin{array}{l}\text { Crystal Size L } \\
(\dot{\mathrm{A}})\end{array}$ \\
\hline$x=0$ & 92.4 & 5.4019 & 30.8536 & 246.04 \\
\hline$x=0.05$ & 91.4 & 5.4052 & 30.8259 & 490.88 \\
\hline$x=0.075$ & 91.7 & 5.4053 & 30.7396 & 569.42 \\
\hline$x=0.1$ & 92.4 & 5.4019 & 30.7105 & 334.39 \\
\hline $\mathrm{x}=0.15$ & 92.9 & 5.4053 & 30.7073 & 425.85 \\
\hline$x=0.2$ & 92.5 & 5.3990 & 30.6508 & 392.31 \\
\hline
\end{tabular}


Figure 1

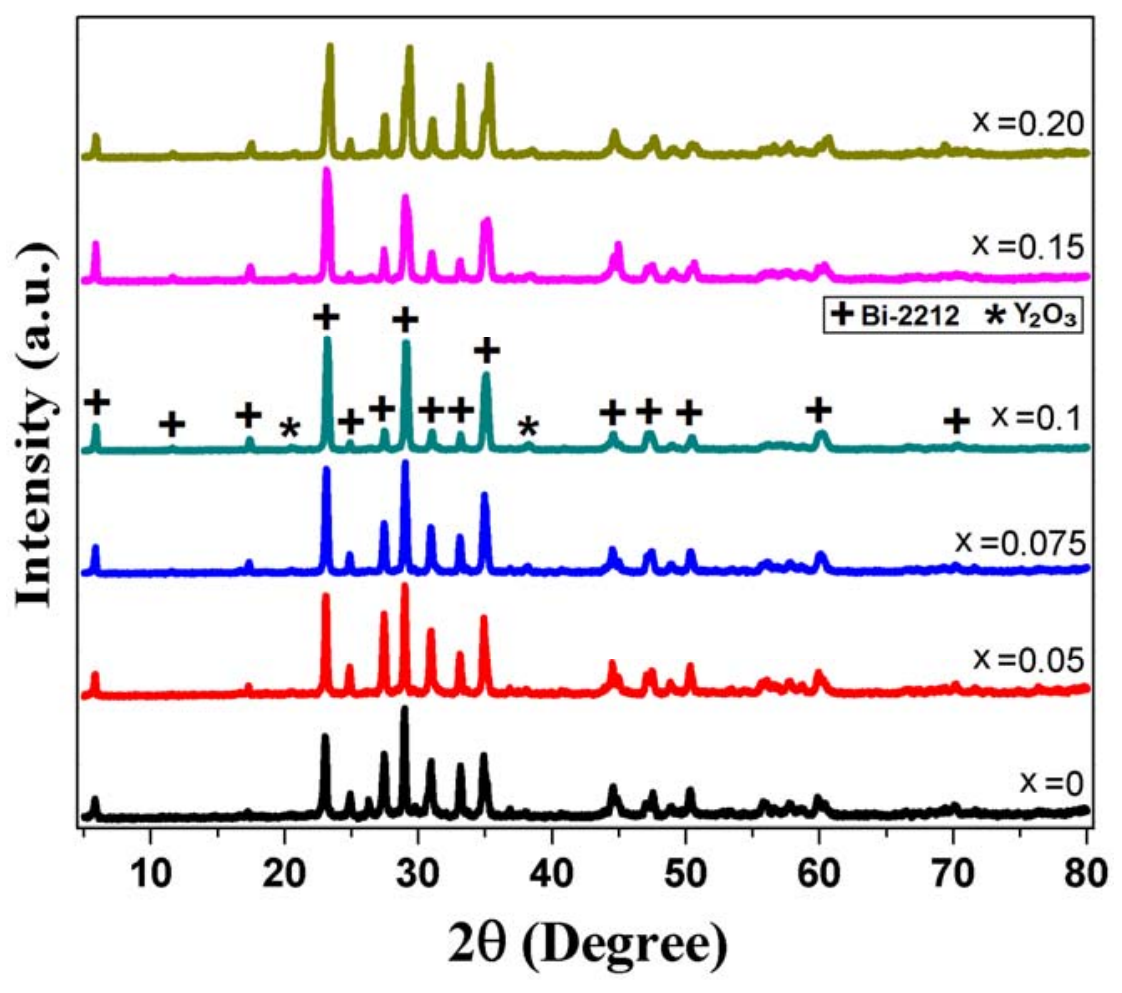


Figure 2

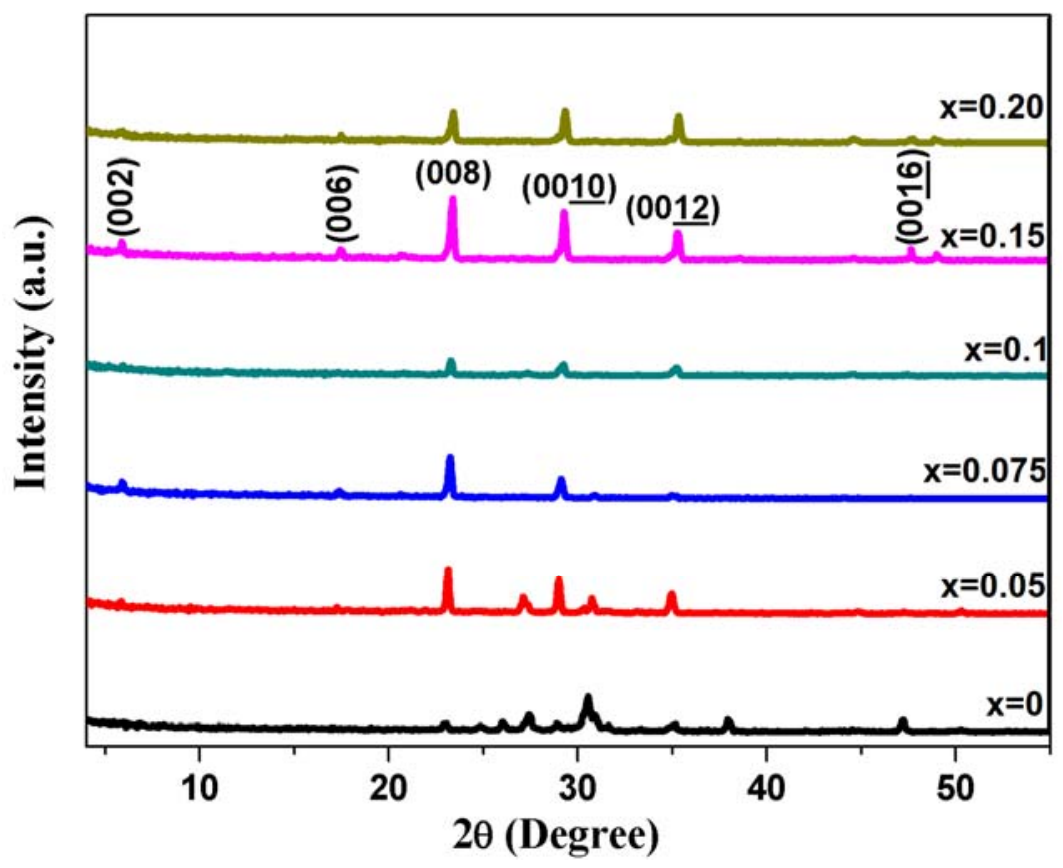


Figure 3

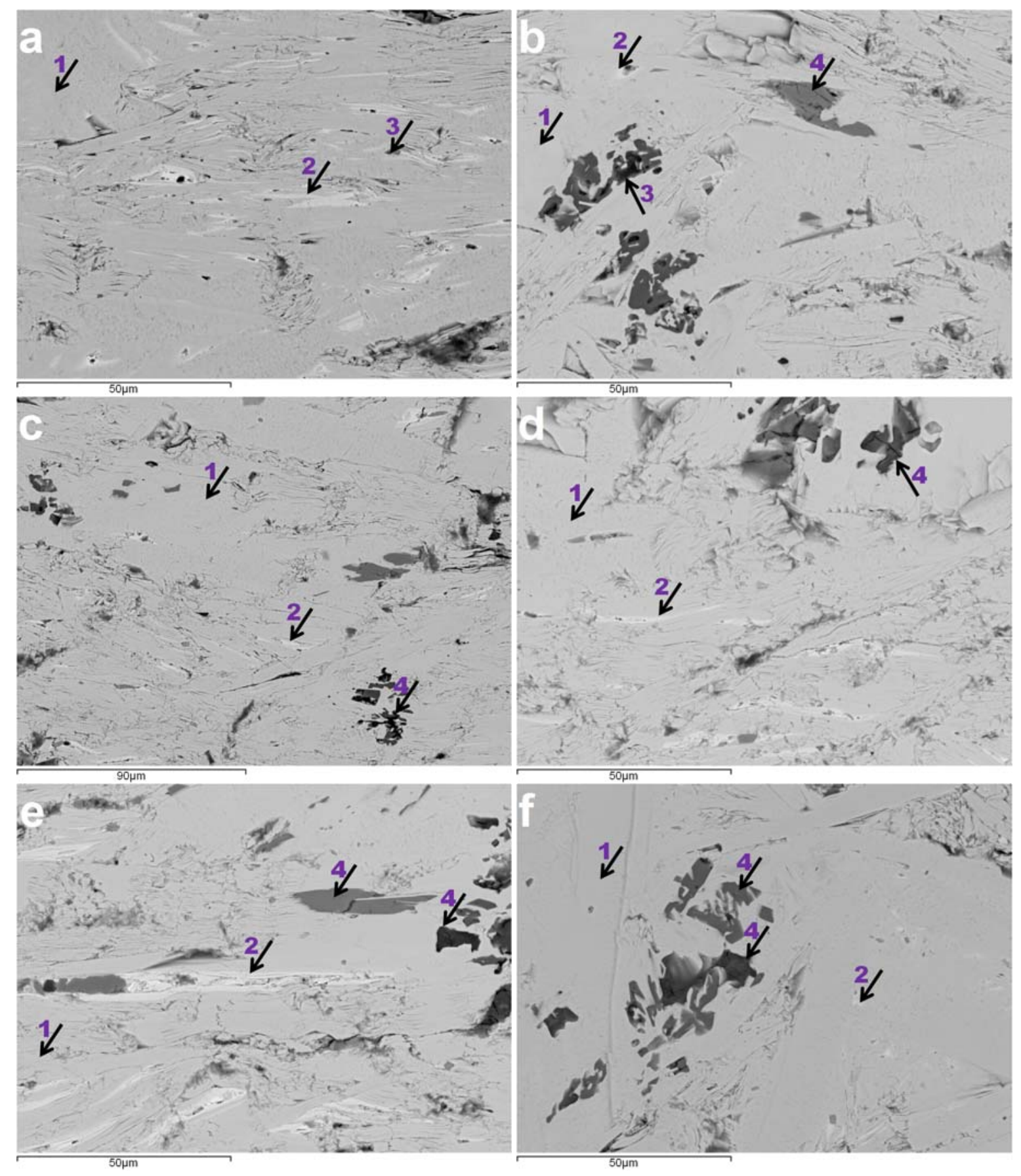


Figure 4

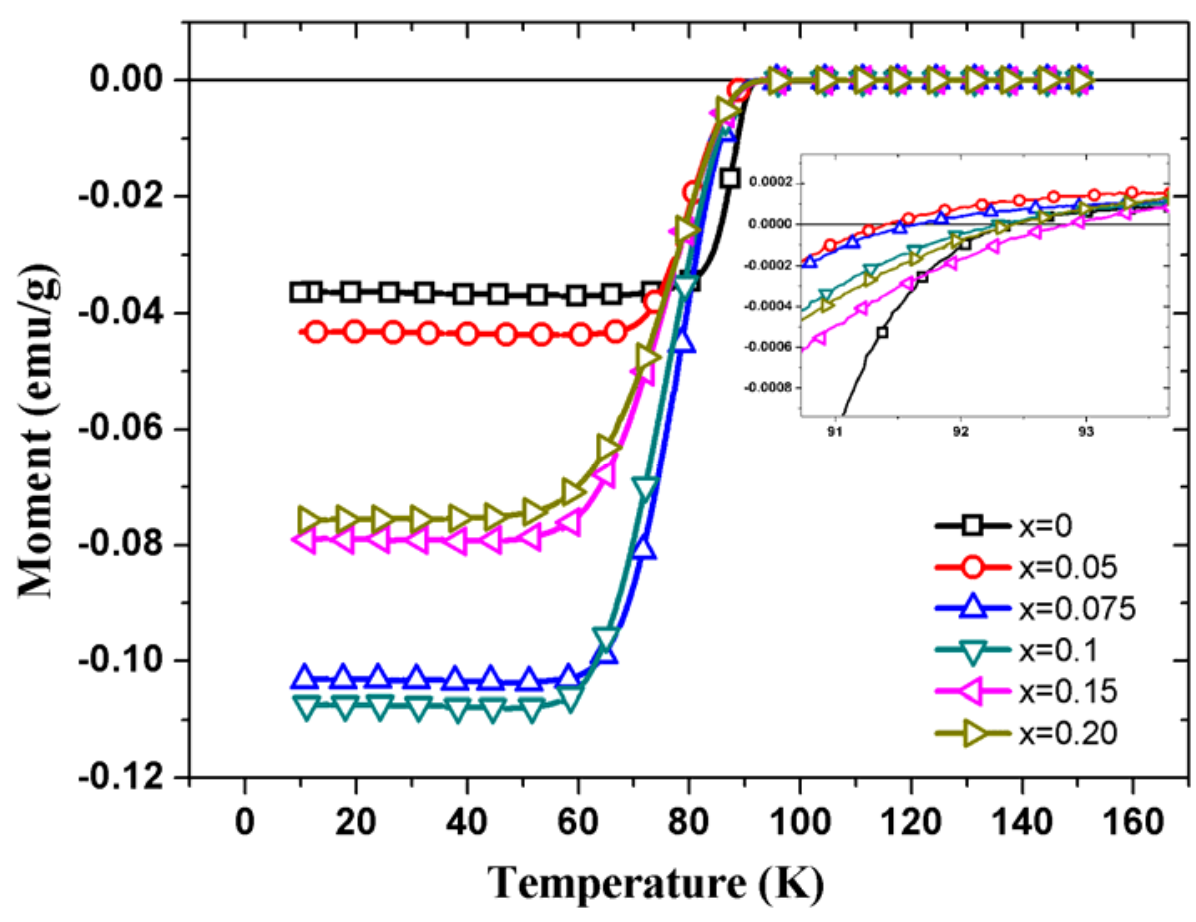


Figure 5

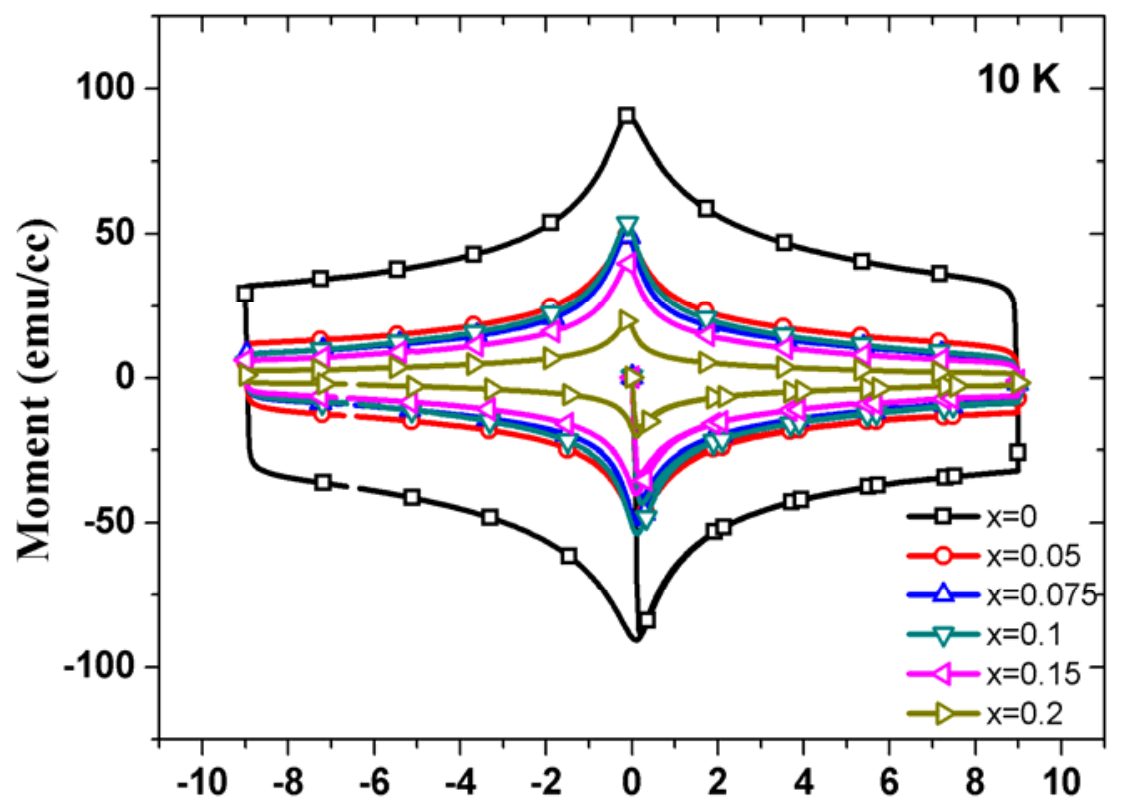

Field (T) 
Figure 6

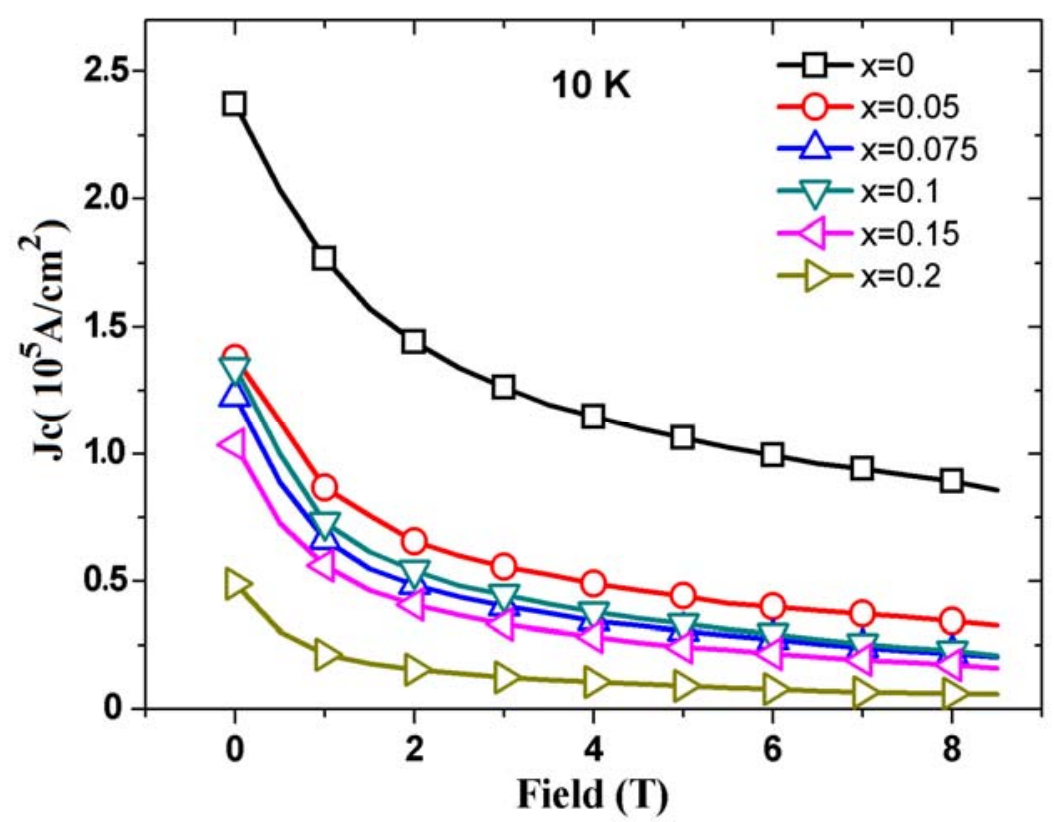

